\title{
As transformações no espaço rural no município de Seropédica-RJ nas últimas décadas
}

The transformations in the rural space in the municipality of Seropédica-RJ in the last decades

Las transformaciones en el espacio rural en el municipio de Seropédica-RJ en las últimas décadas

Les transformations de l'espace rural de la municipalité de Seropédica-RJ au cours des dernières décennies

\section{Márcio de Albuquerque Vianna}

\section{(2) OpenEdition} Journals

Edição electrónica

URL: http://journals.openedition.org/espacoeconomia/16651

DOI: 10.4000/espacoeconomia.16651

ISSN: 2317-7837

Editora

Núcleo de Pesquisa Espaço \& Economia

Refêrencia eletrónica

Márcio de Albuquerque Vianna, « As transformações no espaço rural no município de Seropédica-RJ nas últimas décadas », Espaço e Economia [Online], 19 | 2020, posto online no dia 01 setembro 2020, consultado o 09 setembro 2020. URL : http://journals.openedition.org/espacoeconomia/16651 ; DOI : https://doi.org/10.4000/espacoeconomia.16651

Este documento foi criado de forma automática no dia 9 setembro 2020

(C) NUPEE 


\section{As transformações no espaço rural no município de Seropédica-RJ nas últimas décadas ${ }^{1}$}

The transformations in the rural space in the municipality of Seropédica-RJ in the last decades

Las transformaciones en el espacio rural en el municipio de Seropédica-RJ en las últimas décadas

Les transformations de l'espace rural de la municipalité de Seropédica-RJ au cours des dernières décennies

Márcio de Albuquerque Vianna

\section{Introdução}

1 Embora Seropédica seja um município que possui histórico de produção agrícola desde o século XIX com o bicho da seda, passando por políticas de assentamentos a partir da década de 1930 e, mais ainda, com a instalação de um polo de produção de conhecimento em agropecuária ${ }^{2}$ formado por instituições de ensino, pesquisa e extensão, o seu território vem sofrendo enfraquecimento das atividades voltadas à agricultura familiar desde o final da década de 1990, transformando algumas características do espaço rural. Contudo, esse polo de produção de conhecimento tem articulado muito pouco entre si e juntamente com o poder público local no sentido de reverter esse processo. Historicamente, as instituições que se fizeram presentes nesse território se comportaram com base em uma racionalidade instrumental ${ }^{3}$ (RAMOS, A., 1981), e foram criadas ou se instalaram no local a fim de alcançarem algum tipo de interesse próprio, seja em termos individuais, seja em termos institucionais. Tal racionalidade instrumental se materializou nas ações institucionais a partir de um crescimento exógeno - de fora para dentro - do município, pelo fato de seu território estar inserido na Região Metropolitana do Rio de Janeiro (RMRJ) desde a sua criação em 
$1975^{4}$, embora Seropédica, naquele momento, ainda fosse um distrito pertencente ao município de Itaguaí. $\mathrm{O}$ impacto de todo esse processo é caracterizado como um tipo de intervenção tutorial e não participativo, no qual o agente externo identifica os problemas e as causas de um determinado território e estabelece cursos de ação para que sigam de forma prescritiva como, por exemplo, a instalação de indústrias e condomínios logísticos.

2 Nos últimos anos, o poder público municipal de Seropédica tem apoiado o crescimento econômico do município com a atração de indústrias, empresas mineradoras e empreendimentos logísticos pela proximidade com a Região Portuária de Itaguaí, cujos investimentos em escala global auferem maior PIB - Produto Interno Bruto - quando comparados aos dos pequenos agricultores. Esses investimentos vêm causando impactos socioeconômicos e socioambientais, levando-os a um processo de êxodo rural e desterritorialização (VIANNA, VILLELA e VIDAL, 2015). Outro fator que contribui para o esvaziamento das atividades rurais é a não inclusão dos pequenos agricultores no comércio local e nas agendas de políticas públicas como, por exemplo, o Programa Nacional de Alimentação Escolar do Município - PNAE (VIANNA et al., 2016).

0 processo de intervenção econômica com base na racionalidade instrumental inserida de forma vertical e avassaladora, ao longo da história de Seropédica, diminuiu a possibilidade de um desenvolvimento participativo, sobretudo, relacionado às questões que envolvem a coexistência da agricultura familiar nas agendas políticas locais.

4 Embora o fenômeno do êxodo ainda esteja em curso, percebe-se a tendência e o surgimento de algumas articulações e a criação de campos fortes de poder nos conselhos municipais e em algumas instâncias de resistência (RAMOS, D. et al., 2016), como em associações e em comitês formados por produtores localizados em microbacias hidrográficas, assim como por grupos de agricultores orgânicos que atuam com certa "racionalidade substantiva" (RAMOS, A., 1981) proporcionada pela Ciência Agroecologia. Tais articulações têm buscado a "ação comunicativa" por meio da participação, da gestão e do controle social com o poder público municipal. Mais ainda, buscam o fortalecimento de seus Arranjos Produtivos Locais (APLs) pelas parcerias e projetos com as entidades de pesquisa e extensão instaladas no município, embora em ações ainda pontuais, específicas e desarticuladas. Tais ações vêm surtindo alguns efeitos positivos para o desenvolvimento do território, com ênfase na difusão dos conhecimentos locais, para a inclusão produtiva e comercial dos mesmos e para a segurança e soberania alimentar do município, a fim que haja o provável empoderamento, fortalecimento e resgate da agricultura familiar local. Em síntese, Seropédica tem mostrado um grande potencial para o desenvolvimento territorial sustentável para o meio rural, mas ainda apresenta divergências de interesses institucionais e dificuldades dialógicas entre os seus três principais atores: (i) os gestores do poder público municipal, (ii) as entidades de pesquisa, ensino e extensão instaladas no município e a (iii) sociedade civil organizada e representada pelos agricultores familiares locais.

5 O objetivo geral do presente artigo é apresentar resultados e discussões acerca das mudanças no espaço rural do município de Seropédica face ao crescimento econômico vigente evidenciados em pesquisas desenvolvidas no território (VIANNA, 2017).

6 Como objetivos específicos, o artigo apresentará os seguintes aspectos: (1) contrastar a perspectiva do crescimento econômico com a visão do desenvolvimento territorial sustentável; (2) apresentar algumas características socioeconômicas em recorte 
histórico do território face ao processo de desterritorialização e (3) apontar alguns caminhos e projetos traçados para que haja uma coesão nas propostas de preservação do espaço rural, mesmo com o crescimento econômico exógeno ${ }^{5}$, por meio da participação, do controle e da gestão social nos fóruns de discussão e de promoção de políticas públicas no município.

7 Os aspectos metodológicos da pesquisa contaram com os instrumentos de coleta de dados com base na escolha por pesquisa qualitativa no estudo de caso do município de Seropédica (GIL, 1994), com (i) os documentos analisados, (ii) os atores entrevistados e (iii) a observação participante do pesquisador, cujo método de análise e cruzamento foi realizado com os dados obtidos por meio do método da triangulação (MINAYO, 2006) com as três fontes utilizadas.

8 Após a exposição inicial da complexidade dos fenômenos que envolvem a agricultura familiar no município de Seropédica face às mudanças socioculturais, ambientais e socioeconômicas discutidas neste artigo, serão apresentadas em seguida as dicotomias e contradições que envolvem as questões econômicas, rurais e ambientais nas diversas escalas, dimensões e perspectivas teóricas, as quais serão um pouco mais aprofundadas ao longo do artigo.

\section{A globalização e as transformações do espaço rural local}

9 Na escala global, a complexidade dos fenômenos econômicos, sociais, ambientais e culturais na contemporaneidade requer uma profunda reflexão sobre a sociedade em virtude do notável crescimento do poderio econômico pelo sistema capitalista, o qual elabora estratégias de desenvolvimento de modo desigual, excludente e destrutivo (SANTOS, M., 1994; IANNI, 1997). Entretanto, percebem-se duas características ainda presentes nesse panorama: (i) por um lado, a imposição de modelos e padrões hegemônicos cientificamente aceitos e que são amplamente divulgados no ocidente e, por outro, (ii) a tímida difusão das práticas locais constituídas de significados e sentidos próprios de uma determinada região, com as suas especificidades e peculiaridades. Segundo Hall (2006, p. 80), “as evidências sugerem que a globalização está tendo efeitos em toda parte, incluindo o Ocidente, e a 'periferia' também está vivendo o seu efeito pluralizador, embora num ritmo mais lento e desigual”. Observa-se esse fenômeno, sobretudo, nas regiões rurais.

10 Veiga (2002, p. 58) aponta o caminho do meio, no qual discute que, na fase atual em que se encontra a globalização, "a ruralidade dos países avançados não desapareceu, nem renasceu (...). Essa é a hipótese que parece decorrer tanto de revisão da produção científica sobre o assunto como da observação das mudanças institucionais principalmente no âmbito das políticas públicas da União Europeia".

11 Em uma análise mais específica, a agricultura no Brasil apresenta uma perspectiva bipolar: por um lado, a presença hegemônica do agronegócio capitalista e, por outro, a resistência e a resiliência da agricultura familiar em uma nova perspectiva para o rural (VEIGA, 2002; ABRAMOVAY, 2003). Ambos os modelos coexistem no cenário agrícola do país, muito embora apresentando concepções políticas, administrativas, operacionais, ambientais e filosóficas divergentes. 
12 Na escala local, faz-se necessária a discussão acerca do impacto econômico e ambiental (Imagens 1 e 2) das ações globais na implementação de megaprojetos no município de Seropédica, assim como observados em estudos recentes (VILLELA et al., 2014) realizados em Itaguaí, município vizinho, e que vem impulsionando o crescimento econômico e exógeno na região. Trata-se de um município com historicidade de práticas rurais, mas que, ao longo dos anos, vem sofrendo um processo de “desruralização" (MOREIRA, 2003; PERICO, 2009) e "desterritorialização" (HAESBAERT, 1995). Atualmente, Seropédica é percebida como um polo logístico, industrial e minerador da região, dada a proximidade com a Região Portuária de Itaguaí ${ }^{6}$ a Rodovia Presidente Dutra e o recente Arco Metropolitano (Imagem 2).

13 Rocha (2014, p. 182) destaca que o desenvolvimento do que chama de "nova" Baixada Fluminense, tem como:

[...] entre as ações mais contemporâneas, podemos citar a construção do Arco Metropolitano que, de forma unânime, é apresentado como uma alternativa ao desenvolvimento regional, posto pela posição singular na estrutura logística que a privilegiaria. Logo, a Baixada poderia vivenciar o tal "futuro". Neste mesmo enredo, os agentes que compõem o campo econômico de poder atuam ora na especulação fundiária e imobiliária, através de agentes do mercado imobiliário, e pelo capital industrial, que representado pelo sistema FIRJAN conotam para a Baixada as vicissitudes de "um futuro que já chegou", a rebote da "reestruturação territorialprodutiva" que implica numa nova organização territorial do trabalho.

Figura - Impactos socioambientais: mineração de $\operatorname{areia}^{7}$ e $o$ aterro sanitário de Seropédica.

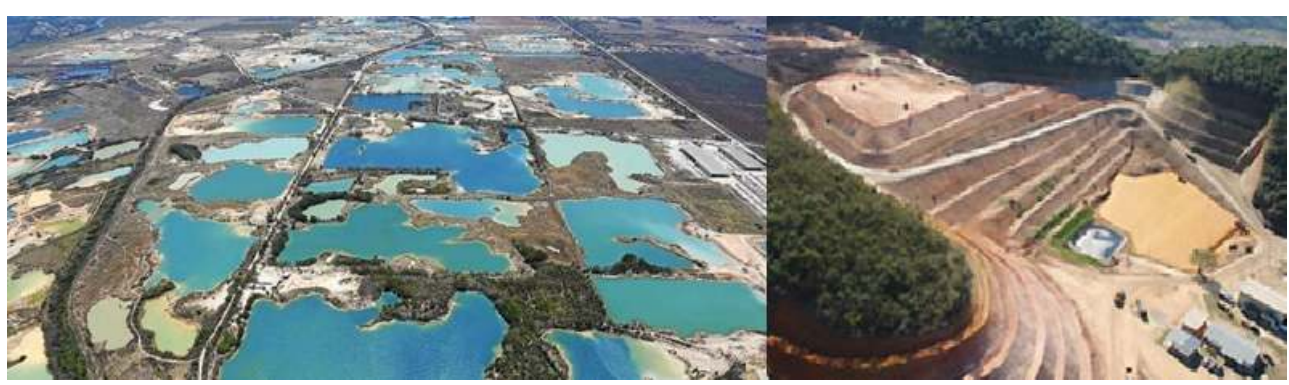

FONTE: Disponível em <http://oglobo.globo.com/sociedade/sustentabilidade/base-da-construcaocivil-areia-um-dos-recursos-mais-valiosos-explorados-do-mundo-14960573> e <http://www.faperj.br/? id=1949.2.8>. Acesso em 20 jan 2015.

Figura 2 - Arco Metropolitano que corta o município de Seropédica, rodovia BR-493.

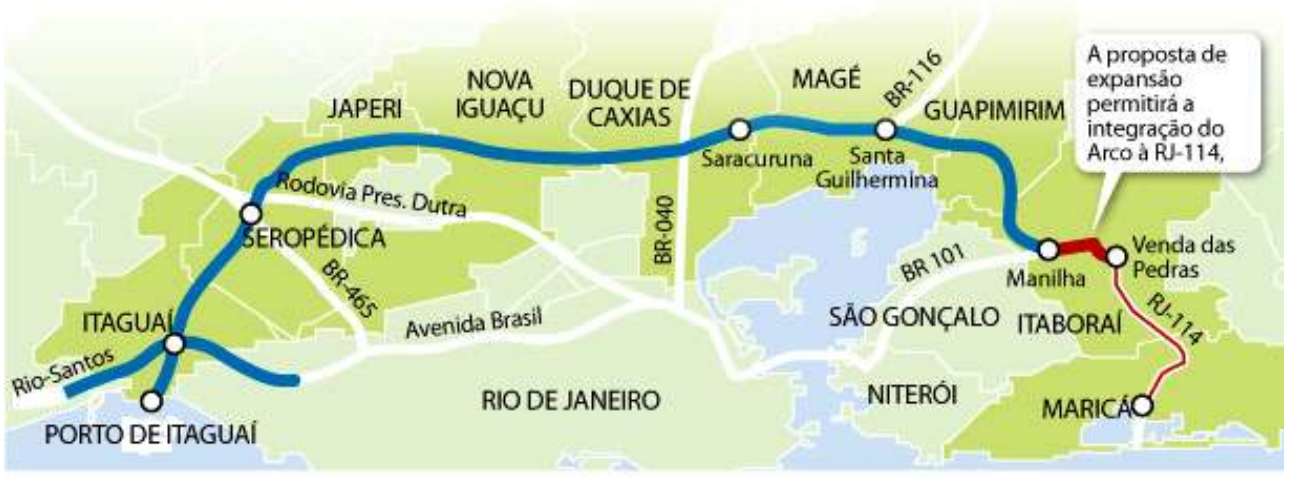

FONTE: Disponível em <http://www.seropedicaonline.com/>. Acesso em 10 jan 2015. 
14 Ao discutir sobre a agricultura familiar nas diversas escalas, Costa e Marinho (2008) apontam que, por muitos anos, essa atividade foi tratada como mera fonte de subsistência para os agricultores, desconsiderando o caráter profissional e os fatores socioculturais desse modo de produção. Este fato levou a futuras discussões quando da implantação de políticas de desenvolvimento. Segundo o Censo Agropecuário (IBGE, 2007), a agricultura familiar equivale a $79 \%$ em relação a todo o pessoal ocupado nos estabelecimentos agropecuários no Brasil. No Estado do Rio de Janeiro, está em torno de $67 \%$.

Em escala municipal, Seropédica, localizada na Microrregião de Itaguaí, na Mesorregião Metropolitana do Estado do Rio de Janeiro (Imagem 3), geomorfologicamente na Baixada Fluminense (ROCHA, 2014), ocupando uma área de $283,79 \mathrm{~km}^{2}$, município emancipado de Itaguaí desde 1995, apresenta, segundo dados do Censo Demográfico realizado em 2010 pelo IBGE (Instituto Brasileiro de Geografia e Estatística), uma população rural de 17,8\%, contra 82,2\% de população urbana (Gráfico 1).

Quadro 1 - Dados da população de Seropédica em dez anos.

\begin{tabular}{|c|c|}
\hline Ano & População total (hab.) \\
\hline 2000 & 65.260 \\
(IBGE) & 72.466 \\
\hline $2007^{9}$ & 78.183 \\
\hline 2010 & \\
(IBGE) & \\
\hline
\end{tabular}

FONTE: IBGE, 2001 e 2011 e contagem da população em 2007 pelo Plano Diretor de Seropédica.

Embora haja um notável aumento populacional (Quadro 1) do município de Seropédica ao longo de 10 anos, percebe-se um avanço no processo de desruralização da população pelas estatísticas, pois, no Censo Demográfico de 2000, o percentual de moradores da área rural era de $20,5 \%$ da população total, sofrendo um declínio para 17,8\%, como mostra o Gráfico 1. 
Gráfico 1 - Tratamento gráfico da população rural de Seropédica em dez anos.

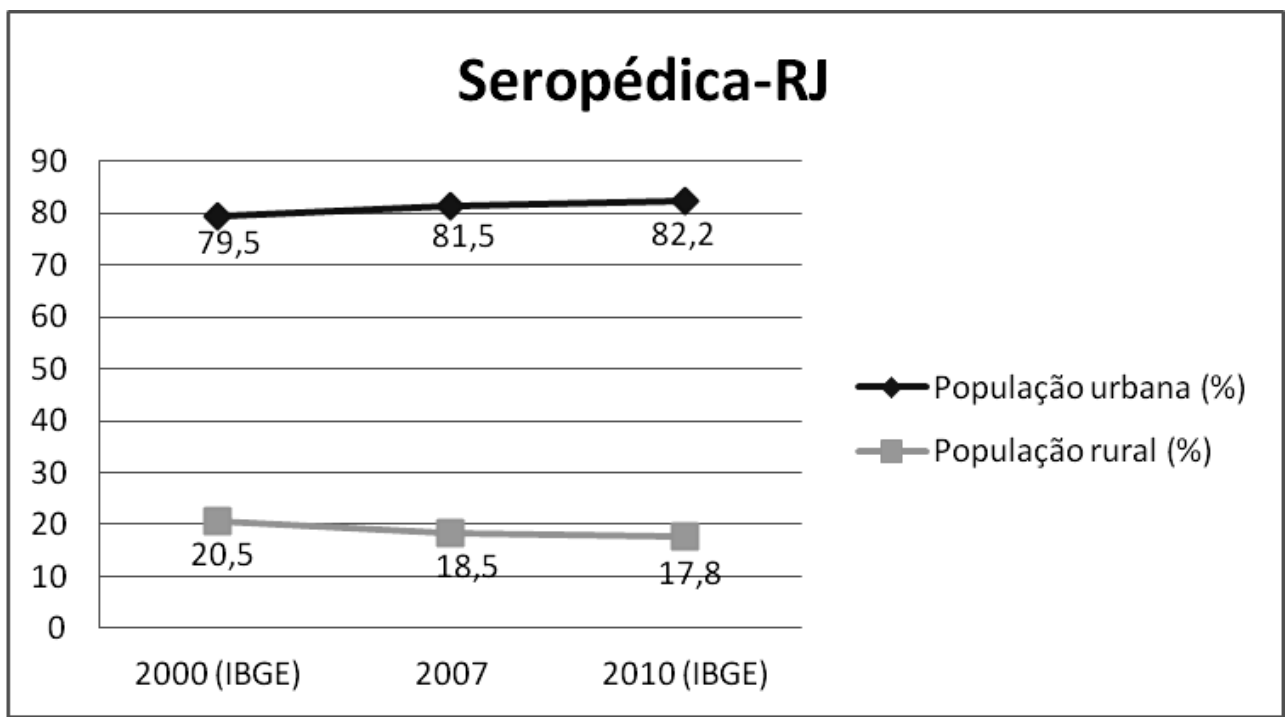

FONTE: Gráfico elaborado pelo autor com base nos dados do IBGE (2001 e 2011) e no censo demográfico municipal de Seropédica de 2007.

17 Com esses dados entende-se que as configurações rural-urbanas no município estão sendo impactadas pelos investimentos de grandes empreendimentos na região ${ }^{8}$, sobretudo acerca da diminuição da quantidade de moradores no meio rural. Além disso, a prefeitura não cria políticas municipais para a agricultura, embora aponte alguns aspectos de desenvolvimento rural em seu plano diretor participativo decenal (SEROPÉDICA, 2006). Um dos aspectos resultantes desse impacto é a possível redução da mão de obra no campo, atraída pela oferta de empregos pelos empreendimentos de grande porte, que podem comprometer a continuidade das atividades desempenhadas pela agricultura familiar no município.

Outro dado importante é o crescimento do PIB (Produto Interno Bruto) do município que saltou de 318 milhões de reais, em 2000, para 938 milhões de reais, em 2010 (IBGE ${ }^{9}$ ) a preços correntes, ou seja, sem contabilizar a inflação acumulada no período - que foi de aproximadamente 89\% pelo IPCA (Índice Nacional de Preços ao Consumidor Amplo). Trata-se de um aumento em torno de $106 \%$ em dez anos (acima do acumulado da inflação calculada pelo IPCA), embora não sejam percebidos efeitos em contrapartidas de investimentos significativos nos segmento sociais como saúde, moradia, educação e, sobretudo, para a manutenção da agricultura familiar, o que pode ser caracterizado como uma das possíveis e principais causas do êxodo rural. 0 próprio rendimento nominal médio mensal per capita dos domicílios particulares permanentes evidencia diferenciação entre a população rural e urbana, sobretudo, quando comparada à média estadual, o que pode estar também contribuindo para o êxodo (Quadro 2). 
Quadro - Dados econômicos de Seropédica comparado ao Estado do Rio de Janeiro.

\begin{tabular}{|l|l|}
\hline Município & \multicolumn{2}{|c|}{$\begin{array}{c}\text { Rendimento nominal médio } \\
\text { mensal per capita dos domicílios } \\
\text { particulares permanentes - 2010 } \\
\text { (RS) }\end{array}$} \\
\hline Seropédica & $\mathbf{6 7 2 , 4 9}$ \\
\hline Seropédica (urbana) & 704,90 \\
\hline Seropédica (rural) & 514,76 \\
\hline Estado do Rio de Janeiro & $\mathbf{1 . 2 3 1 , 5 6}$ \\
\hline Estado do Rio de janeiro (urbana) & $1.254,78$ \\
\hline Estado do Rio de janeiro (rural) & 509,66 \\
\hline
\end{tabular}

FONTE: IBGE (2011).

Quadro - Indicadores socioeconômicos do Município de Seropédica

\begin{tabular}{|c|c|c|c|c|}
\hline \multirow{2}{*}{ Município } & \multicolumn{2}{|c|}{ IDHM } & \multicolumn{2}{c|}{ Índice de Gini } \\
\cline { 2 - 5 } & $\mathbf{2 0 0 0}$ & $\mathbf{2 0 1 0}$ & $\mathbf{2 0 0 0}$ & $\mathbf{2 0 1 0}$ \\
\hline Seropédica & 0,586 & 0,713 & 0,54 & 0,47 \\
\hline
\end{tabular}

Fonte: IBGE, censo demográfico (2001). IBGE, censo demográfico (2011).

Figura 3 - Localização do município de Seropédica no Estado do Rio de Janeiro.
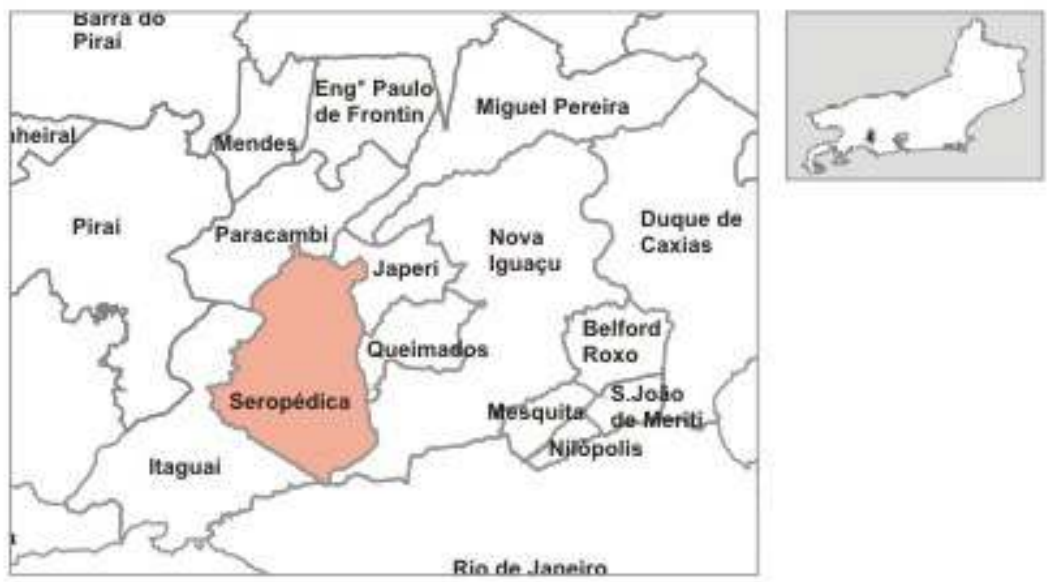

FONTE: http://www.emater.rj.gov.br/imagens/mapa-mini-88.jpg. Acesso em: 16 jul 2020.

\section{Um breve recorte histórico das atividades rurais de Seropédica}

Historicamente, Seropédica ${ }^{10}$, que até o final do século XIX tinha a atividade agrícola e agropecuária com a criação do bicho-da-seda ${ }^{11}$ como sua principal característica socioeconômica na modalidade de produção em larga escala no regime escravocrata, sofreu profundas transformações no seu cenário, e isso pode ser observado em três 
momentos marcantes. A primeira transformação ocorreu com a instalação da UFRRJ ${ }^{12}$ na década de 1940 às margens da rodovia BR-465, que ligava o Rio de Janeiro a São Paulo. Este foi o momento em que a estrutura do município passou a abrigar os alunos $\mathrm{e}$ professores oriundos de diversas regiões do país. O segundo momento foi relativo à integração do município de Seropédica - ainda como parte do município de Itaguaí - à RMRJ em 1975, que aproveitou a infraestrutura já existente de "cidade dormitório" para abrigar trabalhadores e operários em função da notável expansão e desenvolvimento industrial na Microrregião de Itaguaí.

Observa-se um terceiro momento, no qual ocorrem significativas transformações políticas, sociais, culturais e econômicas, pois o município passou a atrair empreendimentos industriais, logísticos e comerciais, que podem estar influenciando negativamente nas atividades rurais. Nesse contexto, a agricultura familiar passa a sofrer retrações, pois as atividades agropecuárias não oferecem um notável rendimento e não contribuem significativamente para o PIB do município. Há ainda uma forte especulação imobiliária em áreas antes agrícolas e agora residenciais e/ou industriais. Também os rendimentos auferidos na construção civil e em outras atividades produtivas levam os agricultores a migrarem de trabalho acelerando o êxodo rural, fato que contribui para um processo de desterritorialização, problemas de segurança alimentar e perda de identidade rural local. Trata-se de um crescimento econômico exógeno que exclui a participação da população local, sobretudo, dos que atuam nas atividades rurais.

21 A possibilidade de haver a transição da mão de obra do campo para as indústrias e comércios, devido à mudança de identidade no município de Seropédica proporcionada pelo impacto do crescimento econômico da região, pode ser entendida como um fenômeno social que não privilegia as noções de desenvolvimento nas suas várias dimensões (SACHS, 2008). Trata-se de um crescimento exógeno, ou seja, de fora pra dentro, chegando a ter investimentos na escala global com a criação do polo industrial e portuário de Itaguaí. Outro fator que pode estar contribuindo para o enfraquecimento da agricultura no município é o pouco estímulo e a baixa participação e mobilização social (PETERSEN e ROMANO, 1999; ROMANO e DELGADO, 2002) dos agricultores familiares, o que pode levar ao surgimento das dificuldades do setor e isolamento dos atores frente às decisões nas políticas públicas locais. Destarte, estes problemas podem estar contribuindo há décadas para o desgaste do tecido social e cultural das famílias, para a perda da identidade local e, consequentemente, para o comprometimento com a segurança alimentar na região, principalmente para as populações mais desprivilegiadas socioeconomicamente.

22 É provável que os agricultores de Seropédica estejam próximos do que Graziano da Silva (1999) classifica como "rurbanos" pela configuração que o município vem estabelecendo ao logo das últimas décadas, sobretudo, pelas ocupações rurais não agrícolas (ORNAs). Ou seja, como ainda há um pouco da preservação da paisagem rural, alguns moradores permanecem utilizando o espaço no campo que se localiza próximo aos centros urbanos, porém sem exercerem a atividade agrícola.

Mesmo com esse cenário de impactação, ao observar os dados do Censo Agropecuário do IBGE (2007) do município de Seropédica, percebe-se que, à época, havia uma significativa representação dos estabelecimentos familiares de produção agrícola (Quadro 4) comparada com os estabelecimentos não familiares, embora a área utilizada seja significativamente menor. 
Quadro - Número de estabelecimentos agrícolas em Seropédica.

\begin{tabular}{|c|c|c|c|c|}
\hline \multirow[b]{2}{*}{$\begin{array}{l}\text { Municí } \\
\text { pio }\end{array}$} & \multicolumn{2}{|c|}{$\begin{array}{c}\text { Agricultura familiar } \\
\text { Lei } n^{\circ} 11.326\end{array}$} & \multicolumn{2}{|c|}{ Não familiar } \\
\hline & $\begin{array}{l}\text { Estabelecime } \\
\text { ntos }\end{array}$ & $\begin{array}{l}\text { Área } \\
\text { (ha) }\end{array}$ & $\begin{array}{c}\text { Estabelecimento } \\
\mathrm{s}\end{array}$ & $\begin{array}{l}\text { Área } \\
\text { (ha) }\end{array}$ \\
\hline $\begin{array}{l}\text { Seropéd } \\
\text { ica }\end{array}$ & 318 & 1647 & 103 & 8229 \\
\hline
\end{tabular}

FonTE: Censo Agropecuário de 2006 - IBGE (2007).

O número mais atualizado do total de estabelecimentos pelo Censo Agropecuário do IBGE de $2017^{13}$ é de 444 , ocupando uma área total de 9.302 hectares no município, cuja população estimada para 2019 é de 82.312 pessoas. Tal dado apresenta um tímido aumento de cerca de 5\% nos 10 anos - entre o Censo Agropecuário de 2006 e de 2017. Embora o documento atual (IBGE, 2017) não diferencie os estabelecimentos classificados como agricultura familiar, a Imagem 4 identifica, com pouca precisão diferentemente do documento de 2017 - o município de Seropédica, onde se encontra entre 60,1 a $80 \%$ de estabelecimentos agropecuários familiares, permanecendo na faixa - mais precisa - de 75,5\% registrado pelo censo agropecuário de 2007.

Figura 4: Faixa de estabelecimentos Classificados como agricultura familiar nos municípios

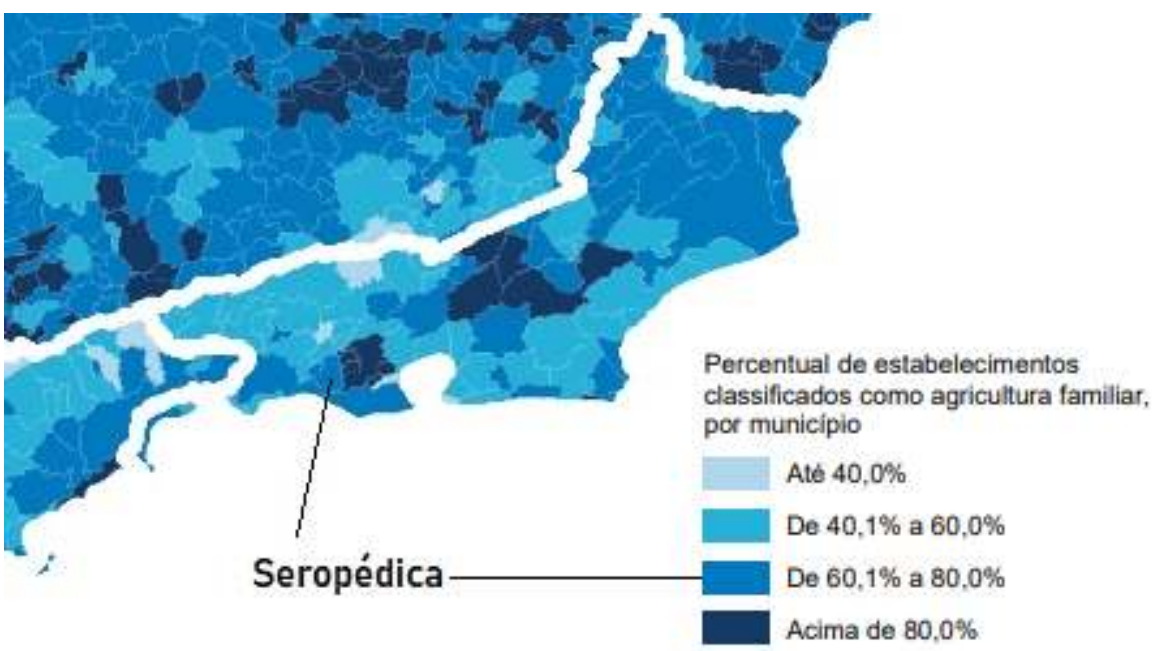

FONTE: Adaptado de IBGE (2017) ${ }^{14}$

Seropédica abriga há décadas o que é considerado por Vianna (2017) como um polo de produção e transmissão de conhecimento em agropecuária, composto por entidades de ensino, pesquisa e extensão. Contudo, questiona-se: qual o grau de envolvimento desses atores institucionais em ações que auxiliem as famílias de agricultores locais no enfrentamento dos problemas advindos das suas atividades nas várias dimensões? Como as instituições governamentais e não governamentais, incluindo a prefeitura municipal, têm contribuído para esse enfrentamento e, consequentemente, para a manutenção da atividade rural no município? Haveria outra possibilidade de desenvolvimento com um caráter socioambiental e econômico para Seropédica, por ter 
em seu território uma instituição como a UFRRJ, com uma vocação e papel fundamental de produção de conhecimento sobre as questões agrárias e agrícolas, mesmo por esse município estar localizado em uma região propensa à instalação de um polo logísticoindustrial e/ou de atividades comerciais? Seria a UFRRJ emblemática de uma instituição onde se faz ciência a partir da perspectiva de uma racionalidade instrumental, com discurso de uma racionalidade comunicativa, "dialógica" de "respeito ao outro" e uma prática científica efêmera na perspectiva das Teorias Críticas?

\section{A agricultura em Seropédica e o espaço rural ao longo dos anos: uma breve análise}

O Município de Seropédica é considerado um "jovem" município com seus 25 anos de existência. Historicamente, a delimitação da antiga Fazenda Santa Cruz - jesuítica - no século XVII se estendia desde a atual Zona Oeste da capital fluminense até Vassouras RJ, no Vale do Paraíba. Com a expulsão jesuítica pelas reformas pombalinas a fazenda passou a fazer parte do Erário Real Português e Imperial Brasileiro, tornando-se um bem público. Com a proclamação da República, em 1889, a Fazenda Santa Cruz passou a ter a denominação Nacional e manteve o status de não ser possível o usucapião ou registro das terras a particulares. 0 município de Seropédica está inserido em terras da antiga Fazenda Nacional de Santa Cruz, bem pertencente ao erário do Estado brasileiro e, posteriormente, responsabilidade do Instituto Nacional de Colonização e Reforma Agrária - INCRA.

No início do século XIX, a região contribuiu para a produção da seda ${ }^{15}$ com a instalação do estabelecimento "seropédico" por José Pereira Tavares em 1836, na qual, evidentemente, se expressou a efeitos da racionalidade instrumental na modalidade do regime escravocrata.

Desta produção da sericultura em nível industrial, que chegou a ter cento e vinte mil pés de amoreira ${ }^{16}$, laboratórios e galpões, surge o nome da localidade "Seropédica", chegando a ter uma importância significativa na economia na época do império até a sua liquidação, em 1862, pelos fatores políticos e pela motivação abolicionista (FRÓES, 2004). Posteriormente, a partir do segundo quartel do século XX, Seropédica passou a ser distrito do de Itaguai ${ }^{17}$, com uma das maiores produções de quiabo, milho, laranja, goiaba e banana do país, até a sua emancipação enquanto município da Baixada de Sepetiba e Fluminense.

A instalação da Universidade Federal Rural do Rio de Janeiro, em 1948, na localidade de Seropédica, então distrito de Itagua ${ }^{18}$, também contribuiu para o desenvolvimento da região, assim como com estudos voltados para a agropecuária local. A universidade foi construída utilizando algumas instalações da antiga fábrica da Seda.

A partir desse período foram assentadas no município aproximadamente 409 famílias pelas diversas políticas de assentamento e distribuição de terras as quais não refletiram em um programa de reforma agrária pleno, sendo muitos filhos de imigrantes japoneses, algumas sob a responsabilidade do INCRA e outras do ITERJ ${ }^{19}$ (GOLINSKI, 2008). Foram criados inicialmente os assentamentos Piranema, Coletivo - no Bairro de Santa Alice - e o Bairro Incra a partir da década de 1930 e, posteriormente, a partir da década de 1980, Sol da Manhã e Eldorado, Filhos do Sol e Sá Freire ${ }^{20}$. É verificado grande percentual de evasão em alguns assentamentos (Tabela 1). 
Tabela 1 - Descrição do número de famílias assentadas em Seropédica.

\begin{tabular}{lcccc}
\hline Assentamentos & $\begin{array}{c}\text { Ano de } \\
\text { Implantação }\end{array}$ & $\begin{array}{c}\mathrm{N}^{0} \text { de } \\
\text { Famílias } \\
\text { Assentadas }\end{array}$ & $\begin{array}{c}\mathrm{N}^{0} \text { de Famílias } \\
\text { Remanescentes }\end{array}$ & $\begin{array}{c}\text { Porcentagem } \\
\text { de Evasão }\end{array}$ \\
\hline Piranema & 1930 & 130 & 75 & $42.3 \%$ \\
Coletivo & 1955 & 582 & 52 & $91.1 \%$ \\
Incra & 1972 & 122 & 94 & $22.9 \%$ \\
Sol da Manhã & 1989 & 52 & 52 & $0.0 \%$ \\
Eldorado & 1993 & 72 & 27 & $62.5 \%$ \\
Filhos do Sol & --- & 19 & 16 & $15.8 \%$ \\
Sá Freire & --- & 200 & 51 & $74.5 \%$ \\
São Miguel & --- & --- & 27 & --- \\
Canto do Rio & --- & -- & 15 & -- \\
\hline
\end{tabular}

FONTE: Golinski (2008, p. 27)

31 Algumas comunidades de pequenos produtores rurais foram criadas em Seropédica a partir do período de assentamento na década de 1960 e as mais recentes na década de 1980, como são os casos dos assentamentos Filhos do Sol, Carretão, Santa Alice e Mutirão Sol da Manhã. A ausência de políticas públicas diminuiu a possibilidade de crescimento e de manutenção das comunidades acerca da produção que apresenta defasagem relacionada à sua capacidade de garantir o abastecimento local e da RMRJ (BRASIL, 2011).

Figura 5 - Mapeamento dos bairros e dos principais assentamentos/comunidades rurais de Seropédica.

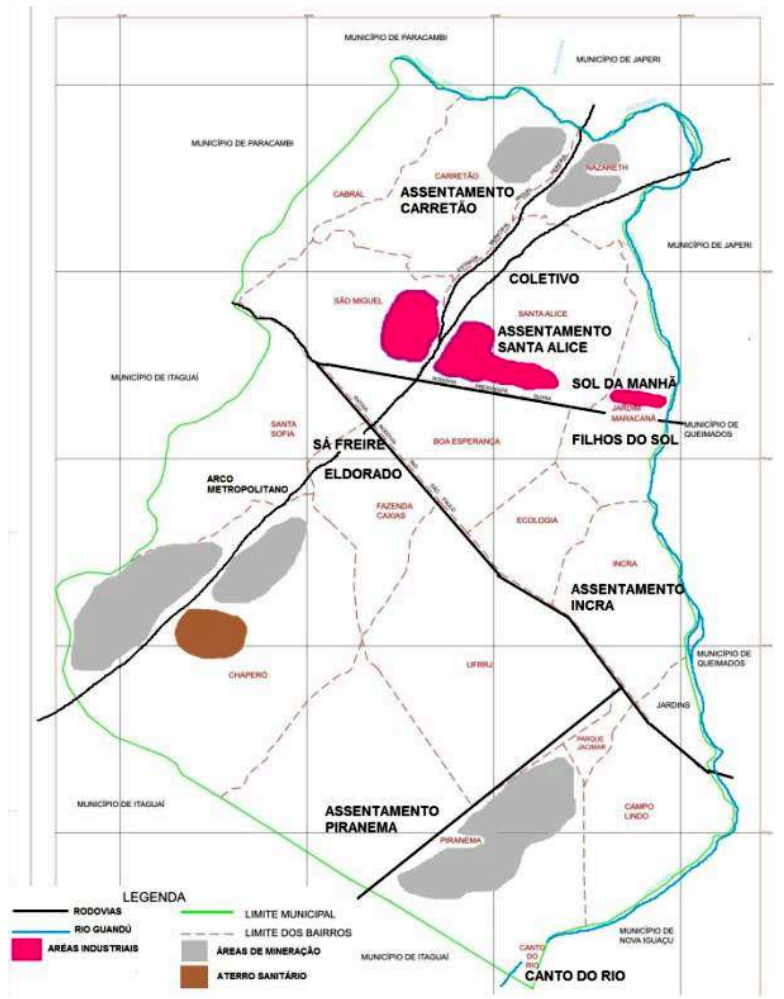

FONTE: Vianna (2017) adaptado do Plano Diretor do Município (SEROPÉDICA, 2006). 


\section{(BRASIL, 2011, p. 87) realizado em 2005, sobre o município de Seropédica}

[...] a situação encontrada nestas unidades produtivas requerem atenção mais detalhada e planejamento adequado para que estes produtores possam sair deste patamar em que se encontram e extrair de fato, de suas atividades, o seu sustento e encontrar um arranjo de atividades produtivas rurais o mais satisfatório possível.

Assim como as questões ambientais em função da extração mineral afetam diretamente a continuidade as atividades exercidas pela agricultura familiar no município, a pouca qualificação e preocupação com o meio ambiente, a ausência de recursos maquinários, entre outros problemas são contabilizados como um rol de adversidades que prejudicam a atividade (BRASIL, 2011). Apesar das dificuldades encontradas, constituise como destaque a produção de alimentos orgânicos no município, segundo o mesmo relatório construído a partir de pesquisa de campo pela UNACOOP ${ }^{21}$ (BRASIL, 2011) em 2009.

Enquanto atualmente alguns desses assentamentos se reorganizaram em forma de associações de agricultores e de moradores, outros agricultores foram mesclados noutras associações de produtores orgânicos e nos Comitês Gestores das Microbacias GOGEMs - do Rio Guandu, pelo Programa Rio Rural do Estado do Rio de Janeiro.

Durante as entrevistas realizadas com agricultores e demais atores do município, ocorridas de fevereiro de 2015 a novembro de 2016 (VIANNA, 2017, p. 59) em vistitas aos seus sítios ou após as reuniões dos conselhos municipais nos quais participavam, ficou evidente o esvaziamento de alguns desses assentamentos ao longo do tempo, bem como a migração de uns para associações com o modo de produção orgânica, na forma de novos APLs com suas governanças e atuações junto à sociedade e às políticas públicas.

36 A história oral dos moradores mais antigos do município pôde revelar aspectos ainda não documentados em estudos anteriores. A Teoria Crítica baseada na racionalidade comunicativa na visão de Habermas (1995) objetiva-se no entendimento "do outro", cujo papel é "dar voz" ao serem reveladas as suas percepções sobre o "mundo da vida". Segundo o agricultor entrevistado da Associação Sol da Manhã que atua na agricultura local há mais de 28 anos, aos 78 anos de idade, o esvaziamento da sua associação devese ao endividamento dos agricultores que perderam as suas terras para agiotas:

Aquilo acabou. A maioria vendeu o sítio. Tem lá o mínimo agora. Quase ninguém vai mais [na sede da associação]. Eu trabalho na roça de segunda à sábado e domingo eu faço uma limpeza lá, porque eu peguei aquilo tudo sujo, cheio de mato. Eu trabalho domingo lá até 4 horas. vou domingo. Eles vendeu não, eles deu de graça pra um tal de 'fulano', certo? Ele tem mais de uns 10 sítios lá dentro. Agiota, sabe? Mixaria teve um que perdeu sabe por quanto? Mil reais... foi passando pra frente [porque a dívida valia] 32 [mil reais], aí não tem juízo, compra quem paga, né?(...) Uns quinze venderam o sítio. Venderam não, deu dado. Pegaram dinheiro a juros, não pagou, $\mathrm{e}$ já viu, né? Foi 'apanhando' o sítio. Uma terra boa.

O esvaziamento da Associação de Santa Alice e Coletivo ao longo dos anos é também apontado no discurso da agricultora a seguir, além da migração dos agricultores para as novas associações de produtores orgânicos como o Serorgânico, cujas ações foram mais fortalecidas por se tratarem de coletivos com um "nicho de mercado" em maior evidência como no Circuito de Feiras Orgânicas do Rio de Janeiro e por terem acompanhamento, apoio e fiscalização da ABIO (Associação dos Agricultores Biológicos do Estado do Rio de Janeiro): 
Até o início da formação do Serorgânico, né, [que é] o grupo aqui de orgânicos, nós tínhamos uma associação que estava mais ativa, aqui de Santa Alice que são produtores convencionais [cerca de 30 produtores]. Só que é aquela coisa né, vai chegando a idade, os proprietários mesmos são os antigos, né. Eles vão se aposentando e os filhos não estão investindo muito nessa área, então os idosos não estão mais investindo em agricultura e, com isso, diminuiu bastante a produção. $\mathrm{E}$ sem contar que nos últimos cinco anos a especulação imobiliária veio e [começaram a comprar as propriedades] (...) Os que eram da associação que encerraram a atividade, ou é porque eles se aposentaram ou porque eles venderam a propriedade, [para] imobiliária. [Antigamente a associação era mais ativa] Nós tínhamos na época em que o meu pai produzia goiaba, só a produção de goiaba do meu pai enchia quase um terço do caminhão. Era uma quantidade bem grande: quinhentas caixas, seiscentas caixas de goiaba, sem contar os outros produtores que existiam na região, né. Acho que existiam na época uns quinze produtores de goiaba aqui. Desses produtores, os remanescentes, [só tem] três produtores. (...) Na verdade, a nossa grande dificuldade aqui é a mão de obra porque as pessoas que estão na propriedade já são de idade. E os jovens, os filhos desses proprietários tão todos na cidade são poucos casos como o Daniel [de 24 anos] que tão aqui tocando a roça. [E pra contratar] é complicado porque tem as obrigações trabalhistas que demandam um custo muito alto. Tem o problema do custo de insumos, também na parte de produção e investimento, que também é complicado.

38 A visão das pesquisadoras do escritório local da PESAGRO em Seropédica com relação à diminuição de agricultores no município corrobora com o exposto pela agricultora da Associação Serorgânico acerca das dificuldades com a mão de obra com o envelhecimento dos agricultores e a não continuidade da atividade por parte dos jovens, com a seguinte fala:

É a questão de não ter nenhum incentivo. Não tem crédito. A maioria aqui é assentamento. Nós já tivemos um apoio muito grande do $\mathrm{MDA}^{22}$, tinha aqueles técnicos do INCRA que davam assistência técnica. A gente se reunia quase que toda semana. Isso tudo, com essa situação as coisas vão se perdendo. Eu acho que é muito por isso: as pessoas vão envelhecendo e os filhos não ficam na terra. Porque, como é que vai ficar? Até hoje é assim. Você vai lá em Santa Alice a estrada é péssima. Até hoje não tem luz, a água é de poço.

Os agricultores entrevistados ao longo da entrevista apontaram que, após a emancipação do município, o único gestor que realmente se importou com a agricultura familiar, oferecendo o apoio que satisfatório, foi o segundo prefeito eleito em 2004, embora tenha sido cassado em 2006 pelo Tribunal Regional Eleitoral. Esse fato é verificado na fala da agricultora da Associação Serorgânico, que aponta que

o início que eu vi aqui em 1987, aí foi decaindo, decaindo... por motivos de não ter ajuda do governo [poder público local] o pessoal começou a vender terra de emboço, e começou a parar a agricultura [...a atuação da Secretaria de Meio Ambiente e Agronegócio do município]é muito frágil, deixa muito a desejar [...] No passado a gente via um monte de coisa acontecer, a gente fazia projetos lá, indicava as necessidades locais [...] a gente tinha mais apoio no passado [...] há oito anos a gente está abandonado total [desde o segundo prefeito]. De lá pra cá foi pancada feia em cima do agricultor. $\mathrm{O}$ descaso é proposital, para enfraquecer o agricultor e eles poderem levar a nossa terra.

Logo, percebe-se, com esse breve recorte histórico documental e da história oral dos atores, que a agricultura de pequeno porte de característica familiar, foi diminuindo ao longo das décadas e, mais especificamente, entre os anos 2000 e 2015 com a especulação imobiliária, com a falta de incentivo, escassez da mão de obra pela não permanência dos jovens, com a desarticulação das associações, pelo endividamento dos agricultores, 
etc. Mesmo a região tendo iniciado com a produção agrícola da seda em larga escala, característica do modo de produção das revoluções industriais as quais se constituíam pela visão positivista da racionalidade instrumental (RAMOS, A., 1981) visando a rentabilidade e os resultados regidos pelas leis do mercado e, posteriormente, ter como resultado as políticas de reforma agrária - mesmo que não ideais - com a criação de associações e assentamentos, cuja expectativa é a cooperação, a emancipação e a autonomia na perspectiva da racionalidade substantiva, passa a ter o sentido inverso ao ser diluída e substituída pelas indústrias e condomínios logísticos que se instalam na região nas últimas duas décadas.

41 Por outro lado, o surgimento de pequenos arranjos de produção orgânica, os quais se nutrem de conhecimentos com base na agroecologia das instituições de apoio à pesquisa e à extensão, como as associações Serorgânico, Serramar e, o mais recentemente criado, Raiz Forte, vem surgindo como resistência ao fenômeno do êxodo rural na região. Além desses novos grupos ainda há a continuidade de produtores individualizados que mantém relações comerciais em feiras da região, para os supermercados locais, assim como com a distribuição para o CEASA da Cidade do Rio de Janeiro.

\section{Considerações finais}

42 A agricultura familiar em Seropédica, nas últimas duas décadas, sofreu fortes impactos políticos, ambientais, culturais, sociais e econômicos, mesmo com todo o seu histórico de assentamentos e com a concentração de instituições de ensino, pesquisa e extensão localizadas em seu território. Foi percebido, a priori, que os impactos econômicos com a proximidade do município com a capital do estado e com a região portuária de Itaguaí, os quais fomentaram a construção do arco metropolitano, ampliou a especulação imobiliária no município com a atração de indústrias e condomínios logísticos. Tal fenômeno, causado pelo desenvolvimento exógeno e de intervenção tutorial e não participativa com base na racionalidade instrumental, levou muitos agricultores familiares a desistirem da atividade agrícola.

43 Tal constatação aponta para o crescimento econômico na região de Itaguaí como uma eminente ameaça à perda da histórica identidade rural de Seropédica, em virtude dos investimentos industriais de grandes dimensões e de alcances globais, o que favorece o êxodo rural. Esses fatores estão fragilizando o tecido sociocultural da agricultura local levando a um processo de desterritorialização, conforme Haesbaert (1995). A saturação das respostas de todos os segmentos entrevistados aponta para o fato de que a chegada das indústrias em Seropédica prejudicou a atividade dos agricultores, o que evidencia tal confirmação. 0 descaso e o abandono do poder público municipal com os pequenos agricultores, como estratégia de enfraquecê-los ao excluí-los das políticas públicas, ocorreu no sentido de oportunizar o crescimento econômico via industrialização.

44 Este artigo buscou apresentar dados mais atualizados do número de agricultores familiares no município. Entretanto, devido à não realização do Censo Demográfico de 2020 e devido ao Censo Agropecuário de 2016/2017 não especificar os estabelecimentos caracterizados pela agricultura familiar, embora tenha havido um tímido crescimento de cerca de 5\% no número de propriedades rurais em 10 anos, torna-se difícil diferenciar as características de tais estabelecimentos. 
Espera-se que o polo de produção de conhecimento em agropecuária localizado no município contribua para o desenvolvimento territorial sustentável de Seropédica, face às mudanças socioeconômicas apresentadas, sobretudo para que o pequeno agricultor local tenha o devido incentivo e apoio do poder público e das instituições de ensino, pesquisa e extensão presentes no território. Com isso, tal apoio poderá fortalecer e preservar a identidade do espaço rural, assim como da atividade agrícola no município, seja ao agricultor individualizado ou àquele pertencente às estruturas organizacionais mais substantivas e participativas, como as associações de produtores orgânicos.

\section{BIBLIOGRAFIA}

ABRAMOVAY, R. O futuro das regiões rurais. Porto Alegre. Editora UFRGS, 2003.

BRASIL. Diagnóstico Territorial: Território Baía da Ilha Grande - Rio de Janeiro. Ministério do Desenvolvimento Agrário - Secretaria do Desenvolvimento Territorial. União das Associações e cooperativas Usuárias do Pavilhão 30. CONTRATO: 0240547-67/2007. PROGRAMA PRONAT, novembro de 2011.

COSTA, L. F. C. e MARINHO, R. J. A. A formação do moderno sindicalismo dos trabalhadores rurais no Brasil. In: COSTA. L. F; FLEXOR, G.; SANTOS, R. (Orgs.). Rio de Janeiro: Mauad X; Seropédica, RJ: EDUR, 2008.

FERNANDES, L. J. O remédio amargo: as obras de saneamento da baixada fluminense (1930-1950). Rio de Janeiro. ICHS-UFRRJ, Dissertação de Mestrado, 1998.

FRÓES, J. N. S. O Brasil na rota da seda: uma contribuição para a recuperação, o enriquecimento e a divulgação da memória de Seropédica, Itaguaí e do Estado do Rio de Janeiro. RJ: Editora Universidade Rural, 2ª edição, 2004.

GIL, A. C. Métodos e técnicas de pesquisa social. $4^{a}$ edição. São Paulo: Atlas, 1994.

GOLINSKI, J. Análise do desenvolvimento econômico e tecnológico dos assentamentos rurais do município de Seropédica-RJ, sob uma concepção de territorialidade. Universidade Estadual do Norte Fluminense Darcy Ribeiro, Centro de Ciências e Tecnologias Agropecuárias. Campos dos Goytacazes, RJ, 2008 (Dissertação de Mestrado).

GRAZIANO DA SILVA, José. O Novo Rural Brasileiro. Campinas, IE/UNICAMP. 1999 (2 $2^{\mathrm{a}}$ edição)

HABERMAS, J. Modernidad: um proyecto incompleto. In: CASULLO. Nicolas (Comp.) El debate modernidad/posmodernidad. Buenos Aires: El Cielo Por Asalto, 1995, $5^{\mathrm{a}} \mathrm{ed}$.

HAESBAERT, R. A desterritorialização: entre as redes e os aglomerados de exclusão. In: CASTRO, I. E., GOMES, P. C. C., CORREA, R. L. Geografia: conceitos e temas. Rio de Janeiro. Bertrand Brasil, p. 165-201, 1995.

HALL, Stuart. Identidade cultural na pós-modernidade. DP\&A Ed., 2006.

IANNI, O. A era do globalismo. $3^{a}$ Ed. Rio de Janeiro: Civilização Brasileira, 1997.

IBGE, Instituto Brasileiro de Pesquisa e Estatística. Censo Agropecuário 2006 - resultados do universo. Rio de Janeiro, IBGE, 2007. 
IBGE, Instituto Brasileiro de Pesquisa e Estatística. Censo Agropecuário 2016 - resultados do universo. Rio de Janeiro, IBGE, 2017.

IBGE, Instituto Brasileiro de Pesquisa e Estatística. Censo demográfico 2000 - resultados do universo. Rio de Janeiro, IBGE, 2001.

IBGE, Instituto Brasileiro de Pesquisa e Estatística. Censo demográfico 2010 - resultados do universo. Rio de Janeiro, IBGE, 2011.

MINAYO, M. C. Técnicas de análise de material qualitativo. In: O desafio do conhecimento - pesquisa qualitativa em saúde. 9ª edição, São Paulo: Hucitec, p. 303-360, 2006.

MOREIRA, R. J. Cultura, política e o mundo rural na contemporaneidade. Revista Estudos Sociedade e Agricultura, número 20, abril de 2003.

PERICO, R. E. Identidade e território no Brasil. IICA, Brasília, 2009.

PETERSEN, P. e ROMANO, J. O. Abordagens participativas para o desenvolvimento local. Rio de Janeiro: AS-PTA/Actionaid-Brasil, 1999.

RAMOS, A. G. A nova ciência das organizações: uma reconceituação da riqueza das nações. Rio de Janeiro: FGV, 1981.

RAMOS, D. A. L., VIANNA, M. A. e VILLELA, L. E. O (Des) Envolvimento Territorial: a Luta dos Agricultores Familiares de Seropédica-RJ por sua Inclusão no Programa Nacional de Alimentação Escolar. In Anais do 3은 SEDRES - Seminário de Desenvolvimento Regional, Estado e Sociedade: A questão regional, uma questão (de) política, Blumenau, 2016.

ROCHA, A. S. "As representações ideais de um território": dinâmica econômica e política, agentes e a produção de sentidos na apropriação territorial da Baixada Fluminense pós 1990. Tese de doutorado. Programa de Pós Graduação em Geografia, UFRJ, 2014.

ROMANO, J. O. e DELGADO, N. G. Os planos municipais de desenvolvimento rural como processos sociais. In: MOREIRA, R.J. e COSTA, L.F.C. Mundo rural e cultura. Rio de Janeiro: Mauad, 2002, p. 179-204.

SACHS, I. Desenvolvimento includente, sustentável, sustentado. Rio de Janeiro: Garamond, 2008.

SANTOS, M., Técnica, Espaço, Tempo: Globalização e meio técnico-científico informacional. Hucitec, São Paulo, 1994.

SEROPÉDICA (Município). Projeto de Lei do Plano Diretor Participativo do Município de Seropédica. Lei 328/06 aprovada em 03 de dezembro de 2006. Disponível em <http:// www.seropedicaonline.com/wp-content/uploads/2014/08/Plano-Diretor.pdf>. Acesso em $13 / 08 / 2020$.

VEIGA, J. E. A face territorial do desenvolvimento. In: Interações. Revista Internacional de Desenvolvimento Local. v.3, n.5, pp. 5-19, Setembro, 2002. Disponível em https:// www.interacoes.ucdb.br/interacoes/article/view/565/602. Acesso em 15 de agosto de 2020.

VIANNA, M. A. A Agricultura Familiar em Seropédica-RJ: Gestão Social, Participação e Articulação dos Atores do Polo de Conhecimento Local em Agropecuária. Tese de Doutorado, PPGECTIA/UFRRJ. Seropédica, 2017.

VIANNA, M. A., KRAEMER, C. F. B., VILLELA, L. E. O papel dos conselhos municipais e dos atores locais para o fornecimento da alimentação escolar pela agricultura familiar em Seropédica-RJ. In: Anais do IX Encontro Nacional de Pesquisadores em Gestão Social/ENAPEGS. Porto Alegre, 2016. 
VIANNA, M. A., VILLELA, L. E. e VIDAL, M. Desterritorialização e articulação entre atores locais: o caso dos conselhos municipais de segurança alimentar e desenvolvimento rural de Seropédica-RJ. In: Anais do XVI ENANPUR, 2015.

VILLELA, L. E., COSTA, E.G. e CANÇADO, A. C. Perspectivas da agropecuária do município de itaguaí face a megaprojetos em implementação no local. In: Organizações Rurais \& Agroindustriais, Lavras, v. 16, n. 2, p. 208-219, 2014.

WEBER, M. Economia e Sociedade: fundamentos da sociologia compreensiva (v.1). Editora Universidade de Brasília. São Paulo: Imprensa oficial do Estado de São Paulo, 1999 [1922].

\section{NOTAS}

1. Este artigo é o recorte da tese de doutoramento de Vianna (2017) com as devidas atualizações dos dados adicionais da situação atual do município em questão.

2. O "polo de produção de conhecimento em agropecuária" instalado em Seropédica, termo criado pelo autor em sua tese de doutoramento em Vianna (2017), é formado por instituições de ensino, pesquisa e extensão como, por exemplo, a Universidade Federal Rural do Rio de Janeiro (UFRRJ), a Empresa Brasileira de Pesquisa Agropecuária (Embrapa) Agrobiologia, a Empresa de Assistência Técnica e. Extensão Rural do Estado do Rio de Janeiro (Emater-Rio), o Colégio Técnico da Universidade Rural (CTUR), a Empresa de Pesquisa Agropecuária do Estado do Rio de Janeiro (PESAGRO-RIO), além da Secretaria Municipal de Agronegócio e Meio Ambiente de Seropédica (SEMAMA) que também atua em atividades de extensão e apoio ao pequeno agricultor.

3. Guerreiro Ramos (1981) com base em Weber (1999 [1922]) e em Habermas (1995) diferencia dois tipos de racionalidade: a racionalidade instrumental cujas ações são baseadas no cálculo e no utilitarismo, na qual não há maiores preocupações com questões éticas, e os fins justificam os meios e, por outro lado, a racionalidade substantiva que possui um amplo espectro, pois transcende em muito a estreita relação que atualmente se faz entre razão e cálculo, como um atributo natural do ser humano com base nos aspectos psicológicos.

4. Fonte: https://www.ipea.gov.br/redeipea/images/pdfs/governanca_metropolitana/ projeto_governanca_oficina1_rj.pdf Acessado em 13 ago 2020.

5. O crescimento econômico exógeno ocorre "de fora para dentro" de forma tutorial com uma forte intervenção dos megaempreendimentos que chegam à região com o apoio do poder público municipal, cuja participação dos atores locais na tomada de decisões é muito fraca como, por exemplo, a dos agricultores familiares. O que se pretende apontar como alternativa ao crescimento econômico "exógeno" nesta pesquisa é a necessidade de que Seropédica busque o desenvolvimento territorial sustentável "endógeno", ou seja, a partir das ações de "dentro para fora" com a participação popular da sociedade civil na criação de políticas públicas do tipo botton up - de baixo para cima - que valorizem práticas de desenvolvimento mais igualitárias e inclusivas.

6. A região portuária de Itaguaí envolve um polo industrial, siderúrgico e petroquímico com a chegada de empresas como a ThyssenKrupp Companhia Siderúrgica do Atlântico (TK-CSA), atual Ternium Brasil, o estaleiro da Marinha do Brasil com a produção dos submarinos nucleares, a USIMINAS, a Petrobrás, a Gerdau, a Companhia Siderúrgica 
Nacional (CSN), a petrolífera LLX, entre outras empresas menores que se instalaram no complexo industrial.

7. Localizado em uma área de $50 \mathrm{~km}^{2}$ nos municípios de Seropédica e Itaguaí, o APL de Piranema é a fonte de $90 \%$ da areia utilizada na construção civil na RMRJ, o equivalente a $70 \%$ de toda a areia utilizada no estado, de acordo com o Departamento Nacional de Produção Mineral (DNPM). Disponível em: <http://www.faperj.br/?id=2074.2.2>. Acesso em 24 jul 2020.

8. Diversas indústrias tem se instalado no município de Seropédica devido a construção da rodovia BR 493 no ano de 2014 mais conhecida como "Arco Metropolitano", que liga o Porto de Itaguaí às demais localidades da Baixada Fluminense assim como à região norte do estado do Rio de Janeiro e impactos ambientais como os areais de Seropédica, o aterro sanitário e as indústrias mineradoras.

9. Fonte: Disponível em <http://www.cidades.ibge.gov.br/xtras/temas.php? lang=\&codmun=330555 \&idtema=125\&search=rio-de-janeiro|seropedica|produtointerno-bruto-dos-municipios-2011>. Acesso em 21 abr 15

10. Até então Seropédica era distrito de Itaguaí, emancipada em 1995, face à edição da Lei n.. 2446 de 12 de outubro do mesmo ano.

11. A denominação "seropédica" foi criada no século XVIII na língua portuguesa para localizar "onde se faz, ou onde se trata da seda", o que originou o nome do lugarejo onde, anteriormente, era um distrito do município de Itaguaí (FRÓES, 2004).

12. A instalação da UFRRJ em Seropédica fez parte de um projeto de saneamento da Baixada Fluminense (FERNANDES, L. J., 1998)

13. Disponível em: https://cidades.ibge.gov.br/brasil/rj/seropedica/pesquisa/ 24/76693. Acesso em 16 jul 2020

14. Fonte: https://biblioteca.ibge.gov.br/visualizacao/periodicos/3096/ agro_2017_resultados_definitivos.pdf. e https://cidades.ibge.gov.br/brasil/rj/ seropedica/pesquisa/24/0. Acesso em 15 jul 2020.

15. Arte desenvolvida na China iniciada no século XVII a.C. segundo algumas lendas.

16. A folha da Amoreira é necessária à alimentação do bicho-da-seda, daí a necessidade da plantação em larga escala.

17. A Vila de Itaguaí surgiu com o início do Caminho do Ouro ligando Paraty ao Rio de Janeiro.

18. A cidade de Itaguaí foi fundada em 5 de julho de 1918.

19. Instituto de Terras do Estado do Rio de Janeiro.

20. Os assentamentos Eldorado, Sol da Manhã e Filhos do Sol foram obtidos após ocupação das famílias assentadas.

21. UNACOOP - União das Associações e Cooperativas de Pequenos Produtores Rurais do Estado do Rio de Janeiro. É uma instituição filantrópica criada para assessorar, viabilizar e fortalecer a comercialização da agricultura familiar no Rio de Janeiro. Fonte: www.unacoop.org.br.

22. O Ministério do Desenvolvimento Agrário (MDA) foi extinto em 30 de maio de 2016, no governo do presidente Michel Temer (2016-2019). 


\section{RESUMOS}

O presente artigo discute as recentes transformações do espaço rural do município de Seropédica-RJ, cujos assentamentos da reforma agrária em diversos momentos, bem como a formação de associações de agricultores familiares com base na perspectiva da agroecologia, vêm sofrendo transformações e impactos negativos em um processo de desterritorialização face às mudanças socioeconômicas ocorridas no território. Esse processo tem relação, sobretudo, com a chegada de indústrias e condomínios logísticos, devido à proximidade do município ao complexo da região portuária de Itaguaí-RJ. A metodologia da pesquisa contou com os instrumentos de coleta de dados com base na escolha por pesquisa qualitativa do estudo de caso, com (i) os documentos analisados, (ii) os atores entrevistados e (iii) a observação participante do pesquisador, cujo método de análise foi o cruzamento dos dados obtidos por meio da triangulação com as três fontes utilizadas. Espera-se que a existência do polo de produção de conhecimento em agropecuária instalado no município possa articular ações sinérgicas no sentido de contribuir para o desenvolvimento territorial sustentável com atividades de extensão que apoiem as ações e a participação da agricultura familiar no território.

This article discusses the recent transformations of the rural space in the municipality of Seropédica-RJ, whose settlements from agrarian reform at different times, as well as the formation of associations of family farmers based on the perspective of agroecology, have been undergoing transformations and negative impacts in a process of deterritorialization in the face of socioeconomic changes in the territory. This process is mainly related to the arrival of industries and logistics condominiums, due to the proximity of the municipality to the complex of the port region of Itaguaí-RJ. The research methodology relied on data collection instruments based on the choice for qualitative research of the case study, with (i) the documents analyzed, (ii) the actors interviewed and (iii) the participant observation of the researcher, whose method analysis was the crossing of data obtained through triangulation with the three sources used. It is hoped that the existence of a knowledge production pole in agriculture and livestock installed in the municipality can articulate synergistic actions in order to contribute to sustainable territorial development with extension activities that support the actions and participation of family farming in the territory.

Este artículo analiza las recientes transformaciones del espacio rural en el municipio de Seropédica-RJ, cuyos asentamientos de reforma agraria en diversas épocas, así como la formación de asociaciones de agricultores familiares basados en la perspectiva de la agroecología, han sufrido transformaciones e impactos negativos en un proceso de desterritorialización ante cambios socioeconómicos en el territorio. Este proceso se relaciona principalmente con la llegada de industrias y condominios logísticos, debido a la proximidad del municipio al complejo de la región portuaria de Itaguaí-RJ. La metodología de investigación se basó en instrumentos de recopilación de datos basados en la elección para la investigación cualitativa del estudio de caso, con (i) los documentos analizados, (ii) los actores entrevistados y (iii) la observación participante del investigador, cuyo método El análisis fue el cruce de datos obtenidos mediante triangulación con las tres fuentes utilizadas. Se espera que la existencia de un polo de producción de conocimiento en agricultura y ganadería instalado en el municipio pueda articular acciones sinérgicas para contribuir al desarrollo territorial sostenible con actividades de extensión que apoyen las acciones y la participación de la agricultura familiar en el territorio.

Cet article aborde les transformations récentes de l'espace rural dans la commune de Seropédica$\mathrm{RJ}$, dont les colonies agricoles de la réforme foncière à différentes époques, ainsi que la formation 
d'associations d'agriculteurs familiaux basées sur la perspective de l'agroécologie, ont subi des transformations et des impacts négatifs dans un processus de déterritorialisation face aux changements socio-économiques du territoire. Ce processus est principalement lié à l'arrivée des industries et des copropriétés logistiques, en raison de la proximité de la municipalité avec le complexe de la région portuaire d'Itaguaí-RJ. La méthodologie de recherche s'est appuyée sur des instruments de collecte de données basés sur le choix de la recherche qualitative de l'étude de cas, avec (i) les documents analysés, (ii) les acteurs interrogés et (iii) l'observation participante du chercheur, dont la méthode d'analyse était le croisement des données obtenues par triangulation avec les trois sources utilisées. On espère que l'existence d'un pôle de production de connaissances en agriculture et élevage installé dans la municipalité pourra articuler des actions synergiques afin de contribuer au développement territorial durable avec des activités de sensibilisation qui soutiennent les actions et la participation de l'agriculture familiale dans le territoire.

\section{ÍNDICE}

Mots-clés: Déterritorialisation ; espace rural ; industrialisation ; Seropédica ; développement. Keywords: Desterritorialization; rural space; industrialization; Seropédica; development.

Palabras claves: Desterritorialización; espacio rural; industrialización; Seropédica; desarrollo.

Palavras-chave: Desterritorialização; espaço rural; industrialização; Seropédica; desenvolvimento.

\section{AUTOR}

\section{MÁRCIO DE ALBUQUERQUE VIANNA}

Doutor em Ciência, Tecnologia e Inovação em Agropecuária - Área de Concentração em Políticas Públicas Comparadas pelo PPGCTIA/UFRRJ. Professor Adjunto III do DTPE/PPGEduCIMAT/IE/ UFRRJ. E-mail: marcioviannamat@ufrrj.br. 